\title{
Büttner, Bengt, Die Pfarreien der Insel Rügen von der Christianisierung bis zur Reformation
}

\section{Adrien Queret-Podesta}

\section{OpenEdition}

\section{Journals}

Édition électronique

URL : http://journals.openedition.org/ifha/1633

DOI : $10.4000 /$ ifha. 1633

ISSN : 2198-8943

Éditeur

IFRA - Institut franco-allemand (sciences historiques et sociales)

Référence électronique

Adrien Queret-Podesta, «Büttner, Bengt, Die Pfarreien der Insel Rügen von der Christianisierung bis zur Reformation », Revue de l'IFHA [En ligne], Date de recension, mis en ligne le 01 janvier 2008, consulté le 22 septembre 2020. URL : http://journals.openedition.org/ifha/1633; DOI : https://doi.org/10.4000/ ifha. 1633

Ce document a été généré automatiquement le 22 septembre 2020.

(C)IFHA 


\title{
Büttner, Bengt, Die Pfarreien der Insel Rügen von der Christianisierung bis zur Reformation
}

\author{
Adrien Queret-Podesta
}

1 Dernier bastion de la religion slave païenne, située au carrefour des mondes slave, scandinave et germanique, l'île de Rügen est un sujet d'étude de choix pour les médiévistes, ainsi que le prouve la thèse de doctorat de B.B., qui a paru - avec quelques modifications - en 2007. Débutant par une courte introduction, ce travail est divisé en cinq parties, organisées de manière chronologique. La première est consacrée à l'histoire des missions d'évangélisation et à la christianisation de l'île, qui s'acheva par l'incorporation au Danemark et à l'évêché de Roskilde, alors que la seconde relate les débuts et l'essor de l'organisation ecclésiastique de 1168 à 1380. La partie suivante ne concerne pas une période, mais décrit la situation des paroisses et du clergé vers 1380 , en profitant notamment de la relative richesse des sources à cette date. Enfin, la quatrième partie traite de l'organisation ecclésiastique au bas Moyen Âge, tandis que la cinquième présente rapidement l'époque de la Réforme et l'introduction du luthéranisme sur l'île de Rügen. Les seconde, troisième et quatrième parties sont à leur tour divisées en sous-parties; la seconde et la quatrième partie en comportent six (contexte, paroisses, clergé paroissial, représentants de l'évêque, prévôt de l'île et prébendes sans droit paroissial) et la troisième n'en compte que quatre (remarques générales sur les sources, églises paroissiales, vicairies et Elemosinen, et prébendes sans droit paroissial). Les cinq parties sont suivies par une courte conclusion, où l'auteur souligne le fort rôle joué par l'évêché de Roskilde sur le développement de l'organisation ecclésiastique de Rügen, mais précise que l'île occupa toujours une position particulière dans le diocèse, notamment à cause de l'influence des villes de Poméranie, en particulier de Stralsund. L'auteur a également joint à ce travail un nombre important de documents annexes de qualité, notamment une longue liste de biographies des membres du clergé de Rügen au Moyen Âge, ainsi qu'une riche bibliographie. 
2 La richesse des annexes illustre très bien l'une des qualités principales de cet ouvrage, à savoir la qualité du travail du dépouillement de sources effectué par l'auteur et la maîtrise du corpus dont il fait preuve. L'étude des manuscrits contenant les listes de bénéfices concernant l'île de Rügen confirme les compétences de l'auteur en matière de codicologie, alors que son étude détaillée du clergé de l'île prouve ses grandes aptitudes dans le domaine de la prosopographie. Mais le grand mérite de B.B. est indéniablement son approche très pertinente, qui évite habilement la tentation de traiter l'île comme une monade isolée et souligne ses liens avec le Danemark, notamment avec Roskilde, mais aussi avec les villes de Poméranie comme Greifswald et surtout la ville hanséatique de Stralsund. Cependant, la qualité de cette démarche est amoindrie par la faiblesse du dossier cartographique, constitué d'une seule carte, présentant uniquement l'île de Rügen, ce qui présente le double inconvénient d'empêcher la visualisation des liens entre l'île et ses voisins et de compliquer la localisation des différentes paroisses et églises par le lecteur peu familier de la topographie de l'île. Le second point faible du travail de B.B. réside dans la présentation de la religion des Rugiens ; en effet, la description proposée par l'auteur contient quelques imperfections structurelles (elle est en effet éclatée entre la première et la deuxième partie) et ne fait pas référence aux plus récents travaux (dont certains sont rédigés en langue anglaise ou allemande) des spécialistes de la religion des anciens Slaves (en particulier les Polonais S. Rosik, L. Słupecki, J. Strzelczyk). Toutefois, malgré ces deux limites, l'ouvrage constitue une étude de grande qualité, qui s'avère précieuse non seulement pour les chercheurs travaillant sur la Poméranie et l'espace baltique au Moyen Âge, mais aussi pour les spécialistes d'histoire ecclésiastique.

3 Adrien Quéret-Podesta

4 (Université Blaise-Pascal, Clermont-Ferrand II) 